\title{
Sustainable community initiatives: a unique partnership and participatory approach
}

\author{
N. Mokhtar \& M. M. Dali \\ Department of Urban and Regional Planning, \\ Faculty of Built Environment, University of Malaya, Malaysia
}

\begin{abstract}
Existing research on partnerships between local governments and communitybased organizations within Local Agenda 21 processes across the globe have embarked primarily on the advantages of partnership within the philosophical discourse of community participation as well as the barriers of such participation and their effects on intended partnership. Both empirical and qualitative findings which mostly cover the cases from the United Kingdom and European countries revealed the need to explore more in-depth aspects of Local Agenda 21 programme implementation. In Malaysia, the study of Local Agenda 21 programme participation and implementation remains deficient. In an attempt to evaluate the nature of partnership and participation through document analysis and participant observation, this qualitative study reports two major findings; first, there is a need for strong leadership within a community-based organization in order to mobilize its local resources, and second; there must be a willingness by the local government to employ external expertise and work closely with the main stakeholders to keep Local Agenda 21 processes growing and improving. Keywords: partnership, local authority, community participation, communitybased organization, sustainable community initiatives, trust, leadership.
\end{abstract}

\section{Introduction}

This study is inspired by Healey's [1] concluding note in her article on Collaborative Planning which brings to light the fact that "failures" of participation initiatives, community mobilization and partnership working in the complex urban governance systems are essentially "windows of opportunities" that contribute to our knowledge in the dynamic process of urban governance. 
An example of such dynamic process is Local Agenda 21, a challenging pursuit towards sustainable development as it involves various stakeholders under the governance of local governments. One of these stakeholders are the communitybased organizations (CBOs). The partnership between the CBOs and their local government forms part of the basis of Local Agenda 21 implementation and due to the nature of partnership and participation, it is always uneasy.

As a multi-cultural satellite city with a population of approximately 700,000 , Petaling Jaya had an opportunity to engage in the pursuit of sustainable development when its city council was among the four selected local authorities out of 145 local authorities nationwide to implement the first round of Local Agenda 21. As of today, Petaling Jaya City Council is a leading local authority in Local Agenda 21 implementation in Malaysia. One successful programme carried out since the inception of the local authority as a Local Agenda 21 pilot project back in 2000 [2], in the view of this study offers significant insights into potential of partnership and participation in the implementation of Local Agenda 21 programmes under the governance of local authorities in the country. The platform of Local Agenda 21 has opened up opportunities for more active partnership between local authority and its local community. Concomitantly, Local Agenda 21 has become an avenue for more rigorous community participation.

\section{Case study and research methods}

This study employs a small case study of an annual programme that invites CBOs to participate in sustainable community initiative programme where award recipients are awarded maximum development grant of RM50,000. In an initial stage of learning about the annual programme which have been carried out for fourteen years, document analysis as well as participant observation have been applied. Among documents analysed were meeting minutes, formal documents pertaining to exercise of the award programme from 2004 to 2014, several judges' review reports on the award, several email correspondence between the team of judges and selected blog entries by the Local Agenda 21 Unit Officer cum the once member of the judges. On the other hand, the technique of participant observation were based on three days of panel evaluations of each participating CBO's presentation on their initiatives, one day of peer assessment where participating CBOs presented their initiatives to the audience of other CBOs and finally the day of the award giving ceremony.

\section{Trust and leadership in partnership and participation}

Current discourse on Local Agenda 21 implementation generally focuses on its potential to increase participation as well as barriers to its implementation [310]. In particular, studies of Local Agenda 21 in Malaysia paid limited attention to the status of its progress [3,5]. Although Local Agenda 21 is based on the principles of both partnership and participation, scholars mainly undermined the importance of partnership process in the implementation of Local Agenda 21. 
Despite growing scholarship of social capital and capacity building within the context of community participation, there is a wide gap in the studies of community participation within the realm of Local Agenda 21. However, one important contribution to the research on relationship between social capital and sustainable development is available in the work of Rydin and Holman [12]. This work on contribution of social capital to sustainable development policy as well as Purdue's evaluation on community leadership and neighbourhood governance form the theoretical framework of this study. Leadership and trust are two aspects of social capital which Purdue [11] blended in his research on neighbourhood governance. As theory of community participation involves the discussion of neighbourhood governance which primarily touches the aspects of community leadership and the element of social capital, which is trust, this preliminary study on the partnership and participation in a case study of a Local Agenda 21 programme in Petaling Jaya attempts to examine the exhibited elements of trust and leadership.

Rydin and Holman [12] categorize the roles of social capital according to different aspects of barriers to implementation of sustainable development policy. Within the context of the case study, two possible conflicts may occur across partnership level among CBOs, the local authority as well as the team of judges. On the other hand, CBOs may have to deal with barriers to community participation due to lack of will, participation and resources. These possible barriers and conflicts are illustrated in the following diagram (Figure 1).

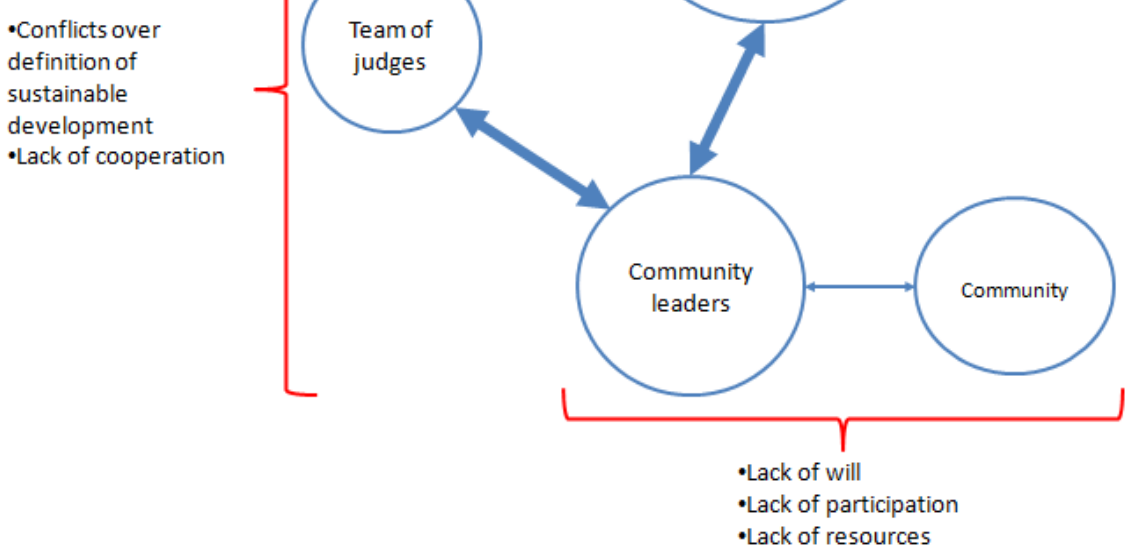

Figure 1: Possible barriers applicable to the case study award programme as summarized by Rydin and Holman [12]. 


\section{Findings}

The process of the award programme, as illustrated in Figure 2 constitutes three main agents, namely the local authority (Petaling Jaya City Council), the team of judges as well as the participating CBOs. This annual programme begins early of the year with the local authority officiates and formally invites CBOs to participate. Invitation letters are sent to all registered CBOs under the jurisdiction of the local authority and consequently $\mathrm{CBOs}$ responded to join in the programme. As part of educating and equipping CBOs with satisfactory level of understanding of sustainable community and awareness of the importance of their participation in the award programme, the local authority organizes a seminar for the participating CBOs which is also attended by the team of judges. In the next stage, while local authority engages with the team of judges for judging preparations, participating $\mathrm{CBOs}$ prepare required documents and presentations of previous and on-going initiatives. Towards the end of the year, visits are conducted at neighbourhood areas of the participating CBOs where evaluations by the team of judges take place with the presence of local authority representatives. Peer assessment is later conducted as part of the evaluation process. The peer assessment day gathers all participating CBOs with the presence of local authority and team of judges to listen to the second round of presentation by community leaders and a part from judging other CBOs, community leaders attended were given opportunities to network and learn from the success and failures of each community's initiatives.

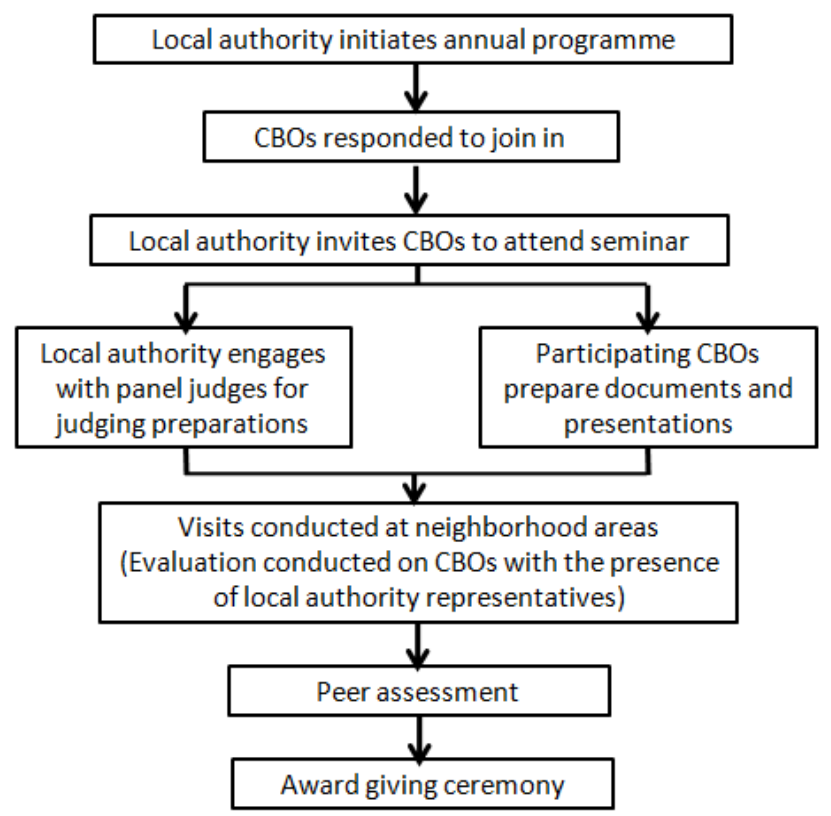

Figure 2: The process of the case study award programme. 
The findings are discussed primarily based on three days observation conducted during the neighbourhood site visits as well as the day of peer assessment whereby participating CBOs gathered to share and learn with and from each other in their common efforts to achieve sustainable community initiatives within the process of Local Agenda 21. The discussion of each finding is supported by findings from document analysis.

\subsection{Community leadership in managing sustainable initiatives}

The team of judges were generally impressed by communities that managed to exhibit charismatic leadership, which is proven by their ability to mobilize their community in managing sustainable initiatives within their neighbourhood. This observation is supported by selected reports by the judges which highlights the fact that the recipients of the awards share a common characteristic, which is strong leadership.

A considerably reputable community leader whom had led his CBO (RA10) to win major prizes in the award for three consecutive years was a full time teacher in a local vocational school. He was reported to be highly charismatic and respected by his community. Rarely can a maintenance body of a high-rise apartment collect fees from house owners but this community leader managed to collect $83 \%$ of the total fees collection. During the peer assessment day which has given the opportunity for participating CBOs to learn from each other, he was asked by his peer on how he had managed to mobilize his community and gather their support in implementing their community initiatives. He revealed his leadership strategy by first learning about his community's common interest and background. Most of the male adults were in the armed forces and therefore he decided that initial community initiatives in building trust and support from his community would be related to safety measures. Equipped with tools and uniforms, this specific group of community were given responsibilities to ensure safety of their neighbourhood. On the other hand, the female adults were acknowledged by their ability to cook. Based on this talent, RA10 has formed its Cooperative body to manage the community's catering services which has contributed additional income to the members of community.

In a similar case, another charismatic community leader was able to solve a major environmental pollution problem where irresponsible trucks were caught dumping waste within his neighbourhood area. He and his community have refused to be bribed and took stern actions against the polluters and reported to the local authority. Such attempts of environmental pollution were not the only challenge faced by the leader of RA11. His leadership skills are also tested by major financial constraints. The disfunctioning maintenance body of his community's apartment failed to collect and manage maintenance fees and have consequently left the neighbourhood dirty and messy. Realising his potential and capacity as the leader of his community, he decided to collect the funds independently as there were urgent needs to improve the physical conditions of the neighbourhood. Huge amounts of fees managed to be raised by this community although they are of a low-income community. The fees collected were used to build all sorts of facilities for the community of all ages. One of 
those facilities is a newly built multipurpose community centre, which uniquely offers gym facilities for its community. Parking spaces for the disabled, transportation facilities for their school children, improved community garden and extra classes for mainly women and children were among the new initiatives organized by the CBO. In addition, RA11's community leadership has shown entrepreneurial skills where more funds are collected through rental of tents. These significant changes and improvements in comparison to their previous progress in earlier years were noticed by the judges during the visit to their neighbourhood. The team of judges have learned that the community leader possesses entrepreneurial and financial management skills, which through these skills, have managed to mobilize support from his community. Consequently, this CBO was awarded the first prize recently.

RT4 is a well-known CBO that has consistently participated in the annual programme and has recorded the highest frequency of award recipient. RT4 was led by a charismatic leader, who has fundamentally encouraged participation of women and youth in their local community initiatives. The presentation by RT4 on the evaluation day was given by the successor of the previous charismatic leader, accompanied by a younger teenage who assisted in briefing parts of their youth participation in sustainable community initiatives. Such performance gives an insight to the team of judges that RT4 acknowledges the importance of leadership succession in ensuring the sustainability of community initiatives. The CBO's preparation for leadership succession has resulted in continuous support from the youth in their implementation of initiatives, particularly the one related to recycling of cooking oil programme. This is proven as the nearby secondary school attended by their teenage community won first prize in collecting and recycling cooking oil competition among schools at the state level.

On the contrary, a few CBOs appeared less prepared during the team of judges' visits to their neighbourhood areas. It was observed that a well-known CBO (RA9) which won a major prize in the previous year as well as three merit prizes in the earlier years, appeared unmotivated and less enthusiastic. It was learned that RA9 was experiencing leadership transition. The new leader was not present during the visit. Panel judges were disappointed when they sort of discontinued the once impressive recycling effort and children's library, which was hoped to impact significantly on the social development of the low income and highly dense community. Development grant awarded by the local authority seem to be wasted. Change of such CBO's leadership has affected the community negatively and suggested smooth transition of leadership is highly important to ensure sustainability of community initiatives through continuity of good neighbourhood governance. This is supported by information from a blog report by one of the judges that discussed the discontinuity of community initiatives programmes due to change in leadership.

\subsection{Mediator role within the partnership}

Factors of trust and leadership within the community may have contributed overwhelmingly in the participation of local community. However, based on observation and document analysis, the study also finds that the unique roles of 
Table 1: Recipient of awards from 2004-2014*.

\begin{tabular}{|c|c|c|c|c|c|c|c|c|c|c|}
\hline \multirow{3}{*}{$\begin{array}{l}\text { CBO } \\
\text { (RA) }\end{array}$} & \multicolumn{10}{|c|}{ Year } \\
\hline & “04/ & $05 /$ & $06 /$ & $07 /$ & $08 /$ & '09/ & '10/ & '11/ & $12 /$ & $13 /$ \\
\hline & & ‘06 & ‘07 & ‘08 & ‘09 & ‘ 10 & ‘11 & ‘12 & ‘ 13 & '14 \\
\hline \multicolumn{11}{|l|}{ RA1 } \\
\hline \multicolumn{11}{|l|}{ RA2 } \\
\hline \multicolumn{11}{|l|}{ RA3 } \\
\hline \multicolumn{11}{|l|}{ RA4 } \\
\hline \multicolumn{11}{|l|}{ RA5 } \\
\hline \multicolumn{11}{|l|}{ RA6 } \\
\hline \multicolumn{11}{|l|}{ RA7 } \\
\hline \multicolumn{11}{|l|}{ RA8 } \\
\hline \multicolumn{11}{|l|}{ RA9 } \\
\hline \multicolumn{11}{|l|}{ RA10 } \\
\hline \multicolumn{11}{|l|}{ RA11 } \\
\hline \multicolumn{11}{|c|}{ RA12 } \\
\hline \multicolumn{11}{|l|}{ RA13 } \\
\hline \multicolumn{11}{|l|}{ RA14 } \\
\hline \multirow{3}{*}{$\begin{array}{l}\text { CBO } \\
\text { (RT) }\end{array}$} & \multicolumn{10}{|c|}{ Year } \\
\hline & $04 /$ & $05 /$ & $06 /$ & 07/ & $08 /$ & ‘09/ & '10/ & '11/ & $12 /$ & $13 /$ \\
\hline & ‘05 & ‘06 & ‘07 & ‘08 & ‘09 & ‘ 10 & ‘11 & ‘ 12 & ‘ 13 & ‘14 \\
\hline \multicolumn{11}{|l|}{ RT1 } \\
\hline \multicolumn{11}{|l|}{ RT2 } \\
\hline \multirow{2}{*}{\multicolumn{11}{|c|}{$\frac{\text { RT3 }}{\text { RT4 }}$}} \\
\hline \multirow{2}{*}{\multicolumn{11}{|c|}{$\begin{array}{l}\text { RT4 } \\
\text { RT5 }\end{array}$}} \\
\hline & & & & & & & & & & \\
\hline \multicolumn{11}{|l|}{ RT6 } \\
\hline \multicolumn{11}{|l|}{ RT7 } \\
\hline \multicolumn{11}{|l|}{ RT8 } \\
\hline \multicolumn{11}{|l|}{ RT9 } \\
\hline \multicolumn{11}{|l|}{ RT10 } \\
\hline RT11 & & & & & & & & & & \\
\hline
\end{tabular}

the team of judges may have contributed significantly to the continuity of the programme.

One of the processes in this annual programme implementation requires participating CBOs to submit to the local authority their profile and records of their community initiatives. This requirement enables the team of judges to prepare themselves by studying the profiles of each $\mathrm{CBO}$ as well as their previous achievements and participation in the award. Upon arrival at sites, team of judges were given warm welcome. Some CBOs were accompanied by their Local Council Member although many CBOs were not. The head of the team of judges introduced the team and herself when visiting new participants. She then asked how the community leaders, among new participants of the award programme understand the concept of sustainable development, which seemed like a probing question to know their level of understanding of the notion of sustainable development and to acquire insights towards their intention to participate in that Local Agenda 21 programme. 

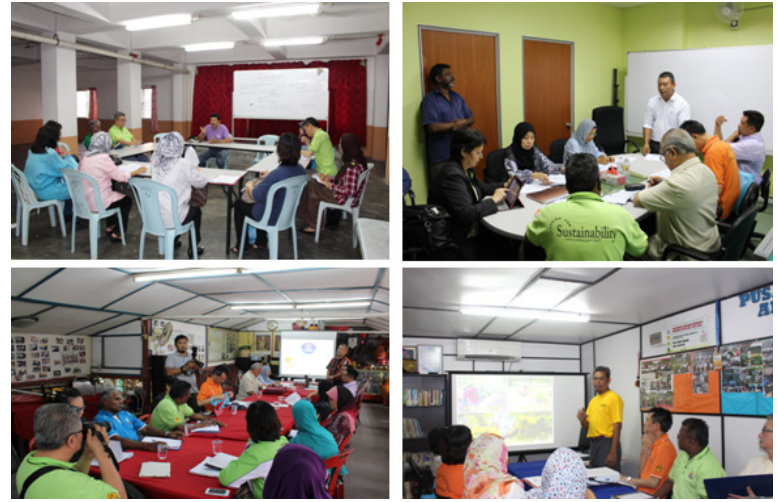

Figure 3: Photos showing presentation by participating CBOs.
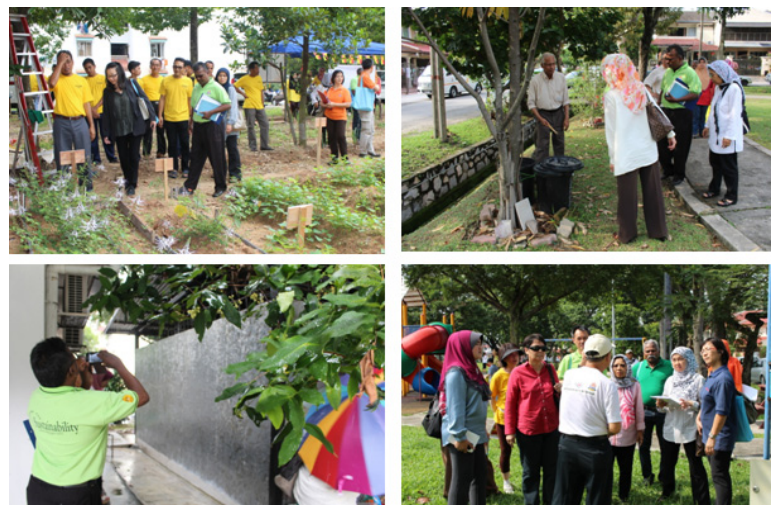

Figure 4: Photos showing site visits to neighbourhood areas.
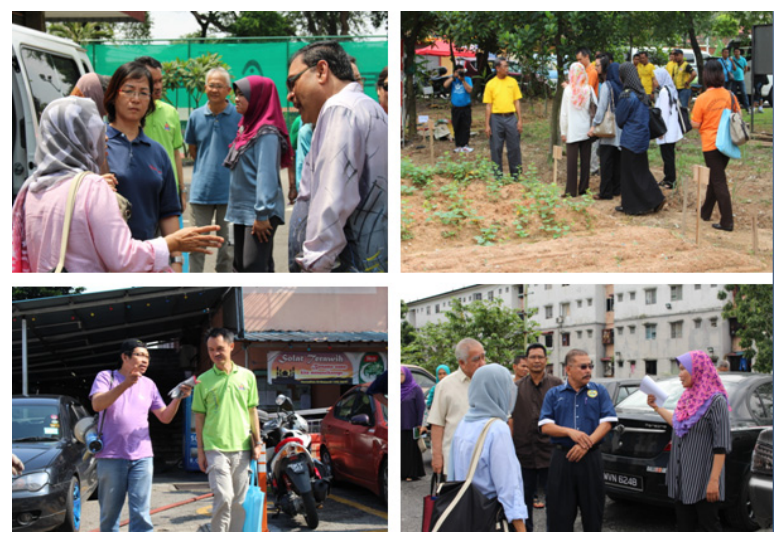

Figure 5: Photos showing discussion and interaction between the team of judges and the community leaders. 

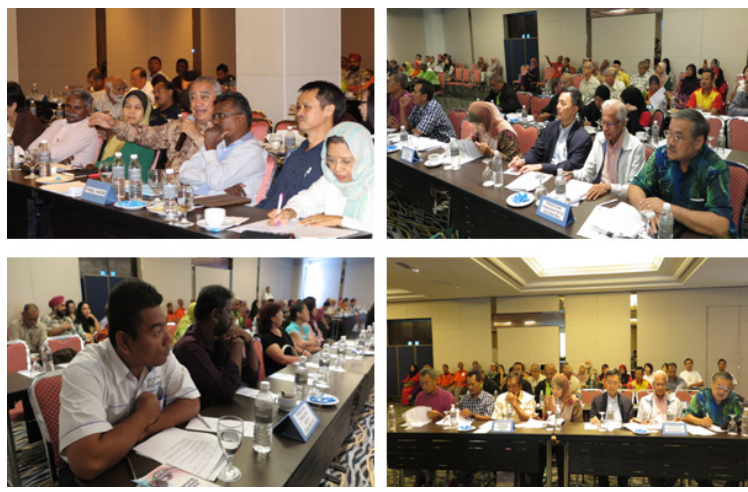

Figure 6: Photos of learning and networking among participants during peer assessment day.

After presentations from the community leaders, the team of judges were taken for tours around the neighbourhood areas to look at different special characteristic of each $\mathrm{CBO}$. Most CBOs have been working on initiatives of building neighbourhood gardens, composting, rainwater harvesting techniques, recycling materials, etc. While so, the team of judges were seen talking to the community leaders, interviewing, giving advice, and at times listening to the CBOs experiences in governing their communities. At times the judges were seen taking opportunities, in any minute they have with each $\mathrm{CBO}$ to encourage them, and advising them on the need to ensure sustainability of community initiatives, based on their presentations. Some of the local leaders and committee members appeared very proud of their community initiatives as they explained in length how they meet their target, and judges played roles in listening, appraising and consulting on how to maintain and improve those initiatives. On the other hand, a number of leaders and committee members were also seen complaining about some issues and problems, while the team of judges listened attentively, some with empathy.

It is important to note that the leader of the team of judges as well as most of other judges remain the same person. The team of judges, over the course of more than a decade have built a common understanding among themselves on their roles in educating the local communities in their pursuit of sustainable development. As they are the same entity, the team of judges are well-known among the CBOs that participate actively in the annual programme. This fact has also given them the opportunity to monitor the progress of participating CBOs. They managed to learn the rise and fall of each participating $\mathrm{CBO}$ and they have built a mutual relationship between them. Community leaders and their communities, particularly the ones that have participated in the annual programme before seem to exhibit trust towards the panel judges. Since they know each other, local leaders acknowledged the judges' expertise, skills and knowledge. The team of judges, in turn, know some background of the local leaders, their performance and their exhibited commitment, which made the process smoother. 


\section{Conclusions}

In evaluating the nature of partnership and participation in the case study of Petaling Jaya City Council's sustainable community initiatives award programme, two elements of social capital can be mapped through the relationship and interaction among the three agents within the process. Based on Rydin and Holman's [12] categorization of possible conflicts and barriers within the process, there exist two main platforms, namely; the partnership level and the community participation level.

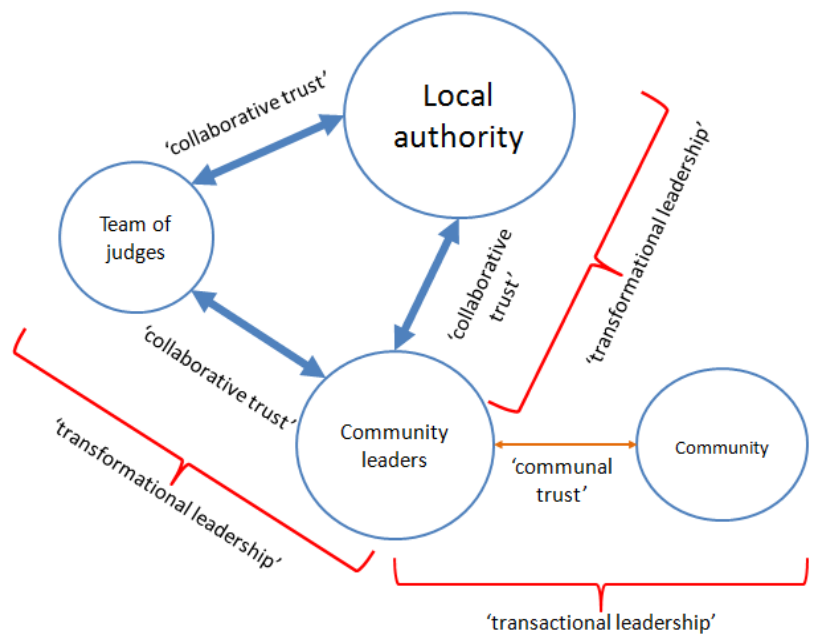

Figure 7: Types of social capital identifiable in the process of the award programme.

At the partnership level which involves the relationship between the community leaders and the local authority as well as between the community leaders and the team of judges, the existence of what Purdue [11] regards as 'collaborative social trust' is required in successful implementation of the whole programme. The ability for community leaders to build and accumulate 'collaborative trust' derived from the characteristics of a 'transformational leader'. At the grassroot level, however, community leaders face barriers relating to participation from their community. Leaders that successfully connect with their community are regarded by Purdue [11] as being successfully building what he calls the 'communal trust'. These leaders are named 'transactional leaders'. In this preliminary study, winners of the sustainable initiatives award programme are found to be led by community leaders who possess either one or both leadership characters. The award programme, which is being emulated by other local authorities in the same state can be considered unique due to the role of the panel judges as mediator within the process. Their roles have impact the process and were built gradually with 'collaborative trust' within the span of fourteen years. 


\section{References}

[1] Healey, P., Collaborative planning in perspective. Planning Theory, 2(2), pp. 101-123, 2003.

[2] Petaling Jaya City Council, Petaling Jaya Sustainable Community Initiatives: Implementation of Local Agenda 21 Petaling Jaya, 2012.

[3] Ahmad, A. H., Ke Arah Pembangunan Mampan Setempat: Pelaksanaan Local Agenda 21 oleh Pihak Berkuasa Tempatan di Malaysia, 6(November), pp. 209-222, 2013.

[4] Geissel, B., Participatory Governance: Hope or Danger for Democracy? A Case Study of Local Agenda 21. Local Government Studies, 35(4), pp. 401-414, 2009.

[5] Mohamed-Osman, M., Syed, A., Rashid, A., \& Ahmad, N., 'Local Agenda 21 in Malaysia: issues and problems faced by the stakeholders in the participation process. Ecocity World Summit, pp. 24-26, 2008.

[6] Tonami, A., \& Mori, A., Sustainable development in Thailand lessons from implementing Local Agenda 21 in three cities. The Journal of Environment \& Development, 16(3), pp. 269-289, 2007.

[7] Harvold, K. A., Consensus or Conflict? Experiences with Local Agenda 21 Forums in Norway. Local Government Studies, 29(4), pp. 117-135, 2003.

[8] Barrett, B., \& Usui, M., Local Agenda 21 in Japan: Transforming local environmental governance. Local Environment, 7(1), pp. 49-67, 2002.

[9] Selman, P., Local Agenda 21: Substance or Spin? Journal of Environmental Planning and Management, 41(5), pp. 533-553, 1998.

[10] Littlewood, S., \& While, A., A new Agenda for governance? Agenda 21 and the prospects for holistic local decision making. Local Government Studies, 23(4), pp. 111-123, 1997.

[11] Purdue, D., Neighbourhood governance: leadership, trust and social capital, Urban Studies, 38(12), pp. 2211-2224, 2001.

[12] Rydin, Y., \& Holman, N., Re-evaluating the Contribution of Social Capital in Achieving Sustainable Development. Local Environment, 9(2), pp. 117$133,2004$. 